\title{
Povo e Elite no Republicanismo Clássico
}

Tiago Losso ${ }^{2}$

\section{Resumo}

No bojo do Republican Revival, há um renovado interesse pelo pensamento político romano. A teoria política tem se nutrido das formulações alicerçadas na tradição republicana de pensamento político desde que o argumento neorromano foi incluído no debate sobre o conceito de liberdade. Correlato a este movimento inicial, atualmente está sendo alargado o conjunto de dilemas que poderia contar com a sugestão republicana. Um tema debatido atualmente é o papel conferido pelo republicanismo ao elemento democrático em seus modelos políticos. A intenção deste paper é analisar três autores-chave do pensamento político romano - Cícero, Salústio e Lívio - e suas respectivas compreensões sobre o papel que cabe ao povo e ao elemento democrático na dinâmica política de Roma. Pretendo convencer o leitor de que a crítica moderna pode estar cometendo um equívoco ao procurar, entre estes autores, justificativas para apontar o povo como protagonista do processo político.

Palavras-chave: Roma. Republicanismo. Povo. Elite.

\section{Introdução}

A Teoria Política contemporânea está sendo cada vez mais alimentada pela tradiçấo romana de pensamento político, especialmente aquela estreitamente vinculada aos autores romanos do século I a.C. e às formulaçôes sobre a política forjadas durante o Humanismo e o Renascimento. Desde que a atençáo ao republicanismo neorromano foi reativada por historiadores

\footnotetext{
1 A pesquisa que embasa este artigo foi realizada durante Estágio Pós-doutoral na Universidade de Wisconsin - Madison (2014-2015) e contou com bolsa Coordenação de Aperfeiçoamento de Pessoal de Nivel Superior (CAPES). Uma versão inicial deste artigo foi apresentada no X Encontro da Associação Brasileira de Ciência Política, que ocorreu em Belo Horizonte, em 2016.

2 Pesquisador do Núcleo de estudos do Pensamento Político. Professor do Departamento de Sociologia e Ciência Política e do Programa de Pós-Pós-graduação em Sociologia Política - Universidade Federal de Santa Catarina.
}

\section{$(\infty))_{\text {EY }}$}

Direito autoral e licença de uso: Este artigo está licenciado sob uma Licença Creative Commons. Com essa licença você pode compartilhar, adaptar, para qualquer fim, desde que atribua a autoria da obra, forneça um link para a licença, e indicar se foram feitas alterações. 
do pensamento político no terço final do século XX, as formulações neorromanas deixaram de ser uma novidade e assumiram o status de fonte relevante para os estudiosos da política.

O conceito de liberdade foi o primeiro tema de análise da teoria política marcado por este retorno ao republicanismo. Ao procurarem uma definição para liberdade tipicamente republicana, para além da dicotomia entre as dimensóes positiva e negativa, autores como Quentin Skinner e Philip Pettit incluíram a tradição republicana no cerne da reflexão contemporânea sobre a política. Assim, após tornar-se uma fonte de consulta para teóricos da política, o republicanismo neorromano expandiu os seus pontos de análise e a abrangência dos contextos intelectuais a serem inspecionados.

Um dos temas que emergiram na teoria política informada pelo republicanismo neorromano é o papel que cabe ao povo no governo de uma comunidade política. Geralmente o republicanismo é tido como refratário ao envolvimento popular na política, mas atualmente é evidente a intenção de alguns teóricos em ressaltar o caráter popular ou democrático da tradição que possui suas raízes na antiga Roma republicana. Aquilo que seria, portanto, o foco inicial da tradição torna-se um contexto que está sendo agora analisado em seus próprios termos e cada vez de forma mais sistemática. Se até o final do século XX o mundo moderno era o locus fundamental de análise para os interessados no republicanismo, sendo a realidade institucional e intelectual da Roma antiga tratada de forma tangencial ou acessória, as recentes publicaçôes ligadas ao republicanismo passam a tratar o republicanismo clássico como ponto principal de análise (HAMMER, 2014; KAPUST, 2011).

Neste artigo pretendo investigar a tradição intelectual republicana, tendo suas consideraçóes sobre povo e elite como ponto de análise. Farei isso lidando com escritos dos três autores clássicos da tradição - Cícero, Lívio e Salústio - que abordaram o papel que caberia ao povo e à elite na condução dos negócios públicos. Acredito que, ao explorar o significado de determinados trechos das obras destes escritores, é possível sustentar que não se encontram arrazoados essencialistas sobre o caráter do povo ou da elite. Seja quando o tema é discutido teoricamente - por exemplo, Cícero e as consideraçóes de Cipião sobre qual o melhor dos governos -, ou quando abordado historicamente - como no caso de Lívio narrando as açôes virtuosas e degeneradas do povo e da elite romana nos anos 
formativos da cidade -, o caráter do povo e da elite de Roma estão circunstanciados e oscilam entre a virtude e o vício.

Proponho que pode ser infrutífera a insistência da crítica moderna em discutir se o republicanismo é popular ou elitista. Pretendo demonstrar que, pelo menos entre os autores romanos do século I a.C., não havia uma opção clara ou apriorística entre povo e elite, mas sim a noção de que ambos são importantes na condução do governo, bem como precisam de permanente vigilância. Defendo também que esta noção somente poderia ter sido avançada pelos autores romanos em tela com o recurso à ideia de uma constituição mista tipicamente romana. Descrita e analisada por Políbio, a ideia de que Roma era governada por uma constituição formada pelo equilíbrio perfeito entre os três princípios constitucionais simples tornou-se de tal maneira arraigada entre os escritores romanos que eles nem teriam se preocupado em elaborá-la sistematicamente. No entanto, a noção de Constituição Mista é o enquadramento de suas intervençóes, permitindo que os escritores romanos associados ao republicanismo apontassem simultaneamente (embora com ênfases eventualmente distintas) as virtudes e os vícios inerentes ao povo e a elite de Roma.

\section{A Teoria Política Contemporânea e o Roman Revival}

Já se tornou lugar comum apontar a emergência da preocupação com a tradiçáo republicana no final do século XX como um movimento que revigorou as discussóes sobre o conceito de liberdade, de forma mais específica, e os estudos da política, de forma geral (URBINATI, 2012, p. 607). Inicialmente o republican revival lidou com o conceito de liberdade oriundo do republicanismo, apontado ou como uma terceira opção além das duas (positiva e negativa) cristalizadas por Isaiah Berlin (1969), ou como uma variação da versão negativa. Na análise de Pettit (1997), a concepção republicana de liberdade é compreendida e nomeada como "não dominação", sendo suas raízes localizáveis entre os escritores romanos do século I a.C., e sua repercussão claramente identificável entre os autores do renascimento italiano e, adiante, entre os escritores que forjaram o pensamento político moderno (pettit, p. 19) ${ }^{3}$. As fontes romanas que, por sua vez,

3 A circulação no mundo moderno dos argumentos avançados pelos autores romanos pode ser conferida, ainda, em: Araújo, 2013; Hammer, 2008. Uma discussão sistemática do debate republicano sobre o conceito de liberdade pode ser visto em Silva, 2010. 
foram consideradas um acessório para compreender a conformação do pensamento político moderno, agora passam a ser consideradas em seus próprios termos (KAPUST, 2011; WALKER, 2006; HAMMER, 2014).

Paralelamente a essa valorização das fontes romanas, o interesse de estudiosos contemporâneos da política desloca-se do conceito de liberdade para uma preocupação com a compreensão do papel que cabe ao povo ou à elite no arranjo político republicano. $\mathrm{O}$ problema poderia assim ser resumido: sendo a tradição republicana de pensamento político a fonte de consulta, quem deve ter o maior peso no governo? Povo ou elite? A busca de uma resposta para esta questão tem mobilizado autores que estão, de uma forma ou de outra, ligados ao republicanismo.

A referência incontornável para o republican revival é Philip Pettit, cujas contribuiçôes não só introduziram o argumento neorromano nos debates sobre liberdade como também expandiram os tópicos que poderiam ser alimentados pela tradição republicana ${ }^{4}$. Segundo Pettit (2012, p. 5), a tradição italiana-atlântica do republicanismo possui três ideias fundamentais: uma concepção de liberdade como não dominação, o elogio à Constituição Mista e uma noção contestatória de cidadania ${ }^{5}$. Já em sua formulação de 1997 - Republicanism: a Theory of freedom and government - o autor irlandês abre um flanco que será explorado por seus críticos: definindo a liberdade como um status, uma situação em que o cidadão está protegido contra interferências arbitrárias, alegando que náo é fundamental a participação constante dos cidadãos nos controles democráticos de sua comunidade. O relevante é a existência de canais que permitam aos descontentes desafiar as decisóes governamentais. De acordo com Pettit (1997, p. 30): "Democratic control is certainly important in the [republican] tradition, but its importance comes, not from any definitional connection with liberty, but the fact that it is a means of furthering liberty".

4 Notadamente: Republicanism: a Theory of freedom and government $\varepsilon$ On the people's terms: a republican theory and model of democracy. Sobre a relação entre teoria política e história do pensamento político, conforme explica Skinner, 1999, no capítulo 3.

5 Pettit (2013) contrasta a vertente italiana-atlântica com a vertente franco-germânica do republicanismo, inaugurada por Kant e Rousseau. 
A democracia contestatória de Pettit precisa de três condiçôes para emergir. Primeiramente, o processo decisório precisa se conduzido de maneira a criar condiçóes para a contestação. Em seguida, a contestação precisa contar com canais formais para ser vocalizada. Por fim, para que a contestação vocalizada seja "absorvida" pelo governo - ela não deve ser apenas vocalizada, mas precisa de alguma forma ser processada e respondida pelo governo (PETTIT, 1997, p. 186 e ss). Nesse arrazoado, ainda que a democracia não seja convencionalmente considerada na tradição republicana, o povo possuiria um papel relevante na dinâmica política da comunidade. Se ao povo não cabe exatamente um papel ativo na vida pública, como a necessidade de participação em assembleias, vale notar que também não é completamente alijado do governo da comunidade. Qual será, então, a natureza da relação do povo com este governo?

A ênfase de Pettit recai sobre as instituiçôes políticas necessárias para a existência de uma comunidade que mantenha a liberdade dos indivíduos. Instituições que devem estar, portanto, a serviço do estabelecimento da liberdade como não dominação no âmbito de determinada comunidade política. Essas instituiçóes deveriam servir, ainda, a outro propósito: permitir que os cidadãos mantenham-se vigilantes aos movimentos dos governantes. Essa preocupação aparece com relevo nas mais recentes formulaçóes de Pettit. Em On the people's terms isso fica evidente, quando o autor sugere que a contestação popular é um poderoso mecanismo para controle de governantes, e que isso pode ser identificado em uma série de contextos históricos (PETTIT, 1997, p. 173). E essa ênfase na vigilância estaria relacionada a um tópico caro aos republicanos: a corruptibilidade dos indivíduos. Embora eles não fossem necessariamente corruptos, existiria sempre a possibilidade de corrompê-los (PETTIT, 1997, p. 247). Sua ênfase nas instituiçóes, portanto, objetiva justamente criar obstáculos para a corrução.

Essa visão sobre a participação popular (ou democrática) encontra resistência entre outros teóricos da política. John McCormick é um destacado crítico da análise avançada por Pettit sobre o papel que cabe ao povo em um arranjo republicano. Na perspectiva de McCormick, o modelo proposto por Pettit teria tão pouco espaço para a participação popular que acabaria por minar a pertinência de suas próprias assertivas, já que resultariam 
em uma noção de liberdade não suficientemente robusta para alcançar as expectativas das comunidades políticas contemporâneas (MCCORMICK, 2011, p. 11).

Com uma análise que acompanha de perto as formulaçóes de Nicolau Maquiavel, John McCormick apresenta argumentos favoráveis ao protagonismo popular no governo. Segundo McCormick, Pettit concebe um republicanismo com claro sotaque aristocrático. Um indicativo disso seria a sua dedicação aos escritores vinculados ao republicanismo que possuem uma visão aristocratizante sobre a política e, de outro lado, sua negligência com expoentes da tradição que teriam uma perspectiva popular (MCCORMICK, 2011, p. 147). Além disso, segue McCormick, Pettit não apenas nutre uma clara precaução em relação ao povo, como também considera a elite mais capaz de produzir bons resultados no controle do governo (MCCORMICK, 2011, p. 158). Um exemplo da cautela exagerada de Pettit em relação ao povo seria o grande temor que demonstra em relação a uma ditadura da maioria. Pettit teria ido além da simples inclusão (de forma absolutamente equânime) do elemento democrático ao lado dos elementos aristocrático e monárquico na conformação do governo, em um arranjo misto nitidamente inspirado nos escritores romanos. $\mathrm{O}$ autor advoga que até mesmo o papel que cabia ao povo na constituição mista romana teria sido subestimado por Pettit (MCCORMICK, 2011, p. 163). $\mathrm{O}$ autor irlandês teria uma nítida simpatia pelo protagonismo aristocrático no governo, relegando o povo a um mero papel contestatório ou vigilante. O povo no modelo de Pettit, de acordo com a crítica de McCormick, seria um mero coadjuvante na conduçáo do governo de uma comunidade.

Eu não pretendo recuperar este debate de forma sistemática ${ }^{6}$. A breve apresentação acima nada faz além de localizar um diálogo específico que, no entanto, ilustra de forma acurada a circulação contemporânea de ideias ancoradas na tradição republicana de pensamento político. Indica, também, como os dilemas relacionados à participação popular na vida pública estão sendo nutridos por um debate, normativo e histórico, que possui clara inspiração

6 Uma análise pormenorizada da ideia de democracia contestatória e de suas críticas pode ser vista em Silva, 20 II. Sobre a relação entre republicanismo e democracia, consultar Urbinati, 20 II, 2012. 
nas instituiçóes e obras romanas. ${ }^{7} \mathrm{Na}$ próxima seção, vou apresentar como povo e elite aparecem nos escritos de autores comumente associados ao republicanismo. Entendo ser possível ao menos indicar que tipo de resposta a crítica contemporânea poderia receber dos antigos escritores romanos, caso lhes perguntasse sobre o papel do povo no governo de uma comunidade política.

\section{Povo e Elite nos escritores romanos}

Em Fundaçóes do Pensamento Político Moderno, no capítulo "A sobrevivência dos valores republicanos", Quentin Skinner chama a atenção do leitor para um detalhe: exatamente quando a maioria das cidades italianas do renascimento caía sob o controle despótico de príncipes, foram formuladas as mais importantes e originais contribuiçôes da doutrina política republicana (SKINNER 1996, p. 160). Esta imagem pode ser útil em outro contexto, vinculado a esta mesma tradição: enquanto Roma assistia ao desmoronamento da República, foram elaboradas as bases para aquilo que seria considerado o marco inicial do pensamento politico republicano. Foi elaborado, então, um elogio a valores, procedimentos e instituiçôes que estariam desaparecendo da realidade romana. Os autores romanos escreveram em uma tentativa de lidar com a crise de seu sistema: "Their thought is born from a deep political crisis, an attempt, amidst corruption, violence, chaos, and despotism to reconstitute a terra recognita - to make sense of, to know again and to recognize, the political world they inhabit" (HAMMER, 2014, p. 25, grifo nosso).

Entre os escritores romanos comumente associados à tradição republicana de pensamento político, muita atenção é dedicada a uma tríade que escreveu no século I a.C.: Marco Túlio Cícero, Caio Salústio Crispo e Tito Lívio. Geralmente se acresce a lista uma influência decisiva para conformação dos escritos políticos típicos do período: o historiador grego Políbio. Escrevendo em meio a ruínas, estes três escritores elaboraram uma poderosa imagem de Roma. A imagem de uma Roma que já não possuíam. É nesta imagem que vou procurar o que cabia ao povo e aos aristocratas em se tratando do governo de Roma.

\footnotetext{
Um aspecto relevante no debate sobre democracia pode ser acompanhado em Urbinati (2014), ilustrando também a penetração dos termos republicanos na Teoria Política contemporânea.
} 
Em seu Tratado da República, Cícero assume estar escrevendo entre as ruínas da República. ${ }^{8}$ Tito Lívio não é menos incisivo. No prefácio de sua História de Roma (AUC), não só é estabelecido que a cidade está absolutamente tomada pela corrupção, como também que o passado é o repositório de valores a serem cultivados. Salústio, por sua vez alega ter encontrado "[...] a audácia, o suborno, a avidez em lugar do decoro, da honradez e da virtude" (Catilina, 3) ao iniciar sua vida pública. Neste mundo em crise, o passado de Roma torna-se o modelo a ser cultivado.

Tito Lívio elaborou uma das mais influentes narrativas sobre a história romana, com o propósito deliberado de apresentar aos seus contemporâneos os valores que teriam inspirado os anos gloriosos da formação de uma comunidade política ímpar. Para nenhum dos autores romanos associados ao republicanismo é tão correto afirmar que os maiores elogios à República escritos em latim foram elaborados enquanto a República ruía. Ab Urbe Condita começou a ser composto entre 27 a.C, quando Roma já era governada por Augusto, inaugurando o Principado que se tornaria Império. ${ }^{9}$ Ainda no citado prefácio, Lívio indica claramente o contraste entre o passado e presente de Roma:

Aliás, se minha paixão por este empreendimento não me engana, nenhuma outra nação foi maior, mais religiosa e mais rica em bons exemplos. Nenhum povo permaneceu tanto tempo inacessível à cobiça e ao luxo, nem conservou tão profundamente e por tanto tempo o culto da pobreza e da economia. A quanto menos riqueza possuiu, tanto menor foi a cobiça. Em nossos dias, com a riqueza veio a cobiça e com a afluência dos prazeres, o desejo de perder tudo e perder-se a si mesmo nos excessos do luxo e do deboche. (AUC, Prefácio).

O passado, além de importante por ser um repositório de virtudes perdidas, é também o momento em que o arranjo institucional que garantiria o florescimento dessas virtudes foi criado e atingiu sua mais exuberante manifestação. Apesar de trilharem caminhos ligeiramente distintos, os três

8 Santo Agostinho atesta a desilusão de Cícero, ao reproduzir um trecho de sua República em que lamenta que apenas pelos erros dos romanos e não por acaso que, mantendo-se o nome, já não tenham uma república. $O$ trecho está em $A$ Cidade de Deus, 2, 21, sendo aceito pela crítica moderna como fiel a um passo perdido. É incluido no início do Liuro V do tratado de Cícero. Cf. Cicero (2008, 5.2; 1928, 5.I)

9 Sobre o título da História de Livio e sobre as datas de sua composição, ver Foster, Introduction. Livy, 1919: xi-xu. Sobre o Principado e a escalada de Augusto à tirania, ver Hammer, 2014, p. 19-25. 
autores aqui considerados compartilham este entendimento. É aqui que entendo ser pertinente acompanhar relação entre povo e elite nos argumentos que cada um deles apresentou sobre o papel desempenhado pelas instituiçôes políticas no alcance da grandeza de Roma.

$\mathrm{Na}$ História de Lívio, esse passado é recuperado com o claro intuito de demonstrar, entre outras coisas, o longo processo de construção das instituiçóes políticas que caracterizariam Roma como uma comunidade política vigorosa. Ao longo desse processo formativo, as tensóes entre o povo e a elite de Roma assumem um papel relevante. Quero salientar uma sequência de eventos, entre os narrados por Lívio, em que o crescente o desconforto da plebe com o tratamento que lhe era dispensado pelos patrícios engendra a criação de uma magistratura plebeia.

Essa sequência inicia com a entrada de um ancião maltrapilho no Fórum, que encontra uma multidão debatendo a inconveniência de partir para a guerra enquanto a cidade era dominada pelos patrícios (AUC, II:23). Os plebeus, que "consumiam-se no ódio aos patrícios, sobretudo por causa da escravidão por dívidas” (AUC, II:23), descobriram que o anciâo maltrapilho era precisamente uma vítima da abjeta situação em que a plebe se encontrava: enquanto lutava por Roma o inimigo invadiu sua propriedade, que foi saqueada e praticamente destruída; como ainda assim os impostos foram cobrados, contraiu dívidas que não somente o obrigaram a vender a propriedade que havia herdado como também contrair dívidas que o lançaram à escravidão. $\mathrm{O}$ tumulto assume outra escala e transborda para toda a cidade, exigindo que Senado e Cônsules decidissem como lidar com uma situação já de sublevação. Enquanto a cidade estava tomada por este tumulto, segue Lívio, chega a notícia de será logo atacada. O Senado então pede que um dos Cônsules, Servílio, use de sua influência junto ao povo para salvar uma "república cercada por tantos perigos" (AUC, II:23).

Falando ao povo reunido em assembleia, o Cônsul inicia alegando que em tal emergência não é possível lidar com as demandas de uma classe que era "sem dúvida a mais numerosa do Estado, mas que apenas constituía uma parte da população" (AUC, II:23, grifo meu). Toda a comunidade precisava ser resguardada, e mesmo não seria justo que a plebe advogasse qualquer vantagem antes de provar sua lealdade à República. Como 
prova de boa fé, o Cônsul anuncia um conjunto de medidas emergenciais: proibia o encarceramento de cidadão que desejasse alistar-se no exército, que os bens de um soldado fossem embargados ou vendidos enquanto ele estivesse na guerra, e que se detivesse seus filhos e netos (AUC, II:23). A intervenção do Cônsul é eficaz e a plebe forma um exército que parte para a guerra e alcança a vitória (AUC, II:25). Não apenas uma vez, mas três em curto período de tempo. Munido da prova de sua dedicação, o povo entáo procura o Senado e o Cônsul para lidar com as demandas represadas pela ameaça que agora desapareceu, uma vez que ao retornar para a cidade o soldado devedor poderia novamente ser encarcerado por seu credor (AUC, II:27). O Cônsul, segue Lívio, é obrigado a tergiversar, dada a recusa terminante do patriciado em atender aos desejos da plebe. Mantendo-se neutro na disputa acaba caindo em desgraça entre patrícios e plebeus. Os primeiros o consideraram fraco e ambicioso, por não ter imposto o desejo do Senado. O povo, por sua vez, o considerava um mentiroso por náo ter cumprido o combinado (AUC, II:27).

As dissensões entre patrícios e plebeus prossegue, e episódios de violência acontecem sempre que um cidadáo é processado ou encarcerado por dívidas (AUC, II:27). Além desses tumultos durante julgamentos e leituras de sentenças, veio nova ameaça externa e a plebe não se alistou (AUC, II:27). A plebe então mostra sua face degenerada, quando "estimulada pela impunidade” passa a cercar diariamente um tribunal, Ápio Cláudio - que dividia o consulado com Servílio e defende os interesses do patriciado manda mesmo prender um cidadáo que parecia ser o líder da rebeliáo. A tal ponto chegou a desagregação da República, com a realização de reuniôes secretas da plebe e o desejo do Senado de evitar este tipo de situaçáo, que Lívio lamenta que "agora havia mil senados, mil assembleias (realizando reuniôes nas Esquilas e no Aventino) e a república se desagregava e aniquilava” (AUC, II:28). O Senado determina aos novos cônsules que procedam ao recrutamento "com o maior rigor possível, pois a ociosidade era a causa da insolência da plebe” (AUC, II:28). A firme recusa da plebe em atender ao recrutamento faz com que os cônsules voltem a prevenir o Senado que grave rebelião está por vir, e que o próprio Senado decidisse como proceder em relação à recusa da plebe em atender ao alistamento antes de ter suas vontades satisfeitas (AUC, II:29). Três partidos emergem 
durante as deliberaçóes no Senado: que se considerasse livre da escravidão por dívidas apenas os ex-combatentes; que se estendesse este direito a toda a plebe e que nada fosse feito além do uso mais força para obrigar a plebe a se alistar (AUC, II:29).

O defensor do terceiro ponto de vista é Ápio Cláudio, que insiste ser necessário conter os ímpetos da plebe, pois "o excesso de liberdade é que tornava o povo mais insolente que desesperado" (AUC, II:29). Nitidamente, Cláudio é um oligarca. Grassa a insolência e arrogância entre patrícios e plebeus. No afã de lidar com isso, é instituído um ditador (AUC, II:30). É escolhido um ditador de uma família que inspirava respeito entre a plebe. Dando um crédito a autoridade do Ditador e aceitando como sinal de boa fé um édito similar aquele de Servílio, a plebe se alista e parte para a guerra, quando novamente demonstra seu valor ao vencer os inimigos de Roma (AUC, II:31). Ao retornar para a Roma, o Ditador encontra nova resistência entre o patriciado em atender os desejos da plebe. Renunciando de forma dramática (AUC, II:31), o ditador lança Roma em um conflito que enseja a retirada da plebe para o monte Sacro (AUC, II:32).

A plebe efetivamente rebela-se contra o patriciado e abandona a cidade, novamente ameaçada por um exército inimigo que se aproximava (AUC, II:32). Instalado o terror entre o patriciado, um deles é escolhido para tentar convencer a plebe a encerrar a sedição e retornar à cidade. Lívio frisa que a razão a escolha é a origem plebeia de Menênio Agripa, que se dirige ao acampamento montado pelos plebeus "além do rio Ânio, a três mil passos de Roma” (AUC, II:32). Agripa vale-se de uma fábula para convencer a plebe da inconveniência daquela revolta: as desventuras de um corpo que para de nutrir o estômago, por considerá-lo ocioso e destino final do esforço dos membros do corpo em obter e preparar alimento. A fábula encerra com o corpo enfraquecido, uma vez que, ao negar alimento ao estômago, isso o incapacitou de gerar energia. A moral: a plebe estava encolerizada com o patriciado da mesma forma que os membros estavam com o estômago e isto poderia comprometer a comunidade (AUC, II:32). Vencida pelo argumento, a plebe volta para Roma onde elegeria magistrados sacrossantos encarregados de zelar por seus interesses (AUC, II:33). 
Os Tribunos da Plebe completarão o tripé constitucional celebrado por Políbio, uma vez que o acesso ao tribunato era vedado a aristocratas e os tribunos possuíam a prerrogativa de resistir a qualquer outro magistrado, menos a um ditador (AUC, II:33). Eram, portanto, a garantia de que os interesses da plebe seriam dali em diante levados em consideração de maneira formal e sistemática. Sua instituição marca o início do conflito das ordens, quando paulatinamente plebeus terão as mesmas prerrogativas políticas do patriciado.

O processo de criação do item final da Constituição Mista é marcado, note-se, pelo intenso conflito entre patrícios e plebeus. Ao longo do trecho Lívio traça as características negativas para plebeu e patrícios. A licenciosidade da plebe (cercando um tribunal) seria insuflada pela arrogância da aristocracia (Ápio Cláudio e seu desprezo pela plebe) e poderia ser contida pela virtude de um patrício (Menênio Agripa ou Servílio). A plebe poderia ser virtuosa também - vide as diversas vezes em que aceitou sinais de boa fé enviados pelos patrícios, mesmo depois de ter outros compromissos desrespeitados. A narrativa de Lívio parece confluir para a criação de um leito, uma espécie de mecanismo capaz de lidar com as oscilaçóes de caráter que marcam plebeus e patrícios. A constituição mista cujo nascimento foi narrado por Lívio é teorizada por Marco Túlio Cícero no primeiro tratado dedicado exclusivamente dedicado à política escrito em latim. Em sua Repúbli$c a$, Cícero avança uma visão não essencialista, também presente em Lívio, sobre patrícios e plebeus. Cipiáo possui elogios e reprimendas para patrícios e plebeus ao longo da sua exposição sobre a melhor das constituiçóes.

A discussão sistemática de Cícero sobre as diferentes formas de governo está registrada no primeiro livro de seu Tratado da República (Rep), diálogo que teria envolvido uma série de figuras importantes de Roma em 129 a.C. ${ }^{10} \mathrm{O}$ principal interlocutor do diálogo é Cipiâo Africano Emiliano, retratado como alguém que aliou a experiência prática e a educação doméstica romana (Rep, I.36) ao trato com as letras gregas (Rep, I.34). Além da capacidade intelectual, Cipião é louvado por ter sido Cônsul e o general que derrotou Cartago em 146 a.C.

10 Sobre a composição do Tratado da República, ver a introdução em Cícero, 1928. 
Seguindo sugestão de Lélio, Cipião inicia sua exposição definindo precisamente o que será tratado - uma República "Portanto, res publica 'Coisa Pública' é a res populi 'Coisa do Povo'. E povo não é um qualquer ajuntamento de homens congregado de qualquer maneira, mas uma multidão associada por um consenso jurídico e por uma comunidade de interesses." (Rep, I:39)."'

Definido o tema da conversa, Cipião prossegue estabelecendo que “[...] todo o povo, que é tal ajuntamento de uma multidão, conforme referi, toda cidade, que é a organização de um povo, toda Coisa Pública, que, como disse, é a Coisa do Povo, devem ser regidos por um órgão de governo para serem duradouros" (Rep, I.41). Acrescenta, então, que este órgão de governo deve ser confiado a um, a alguns ou a muitos, iniciado a apresentação de uma tipologia comum ao pensamento político do mediterrâneo, ${ }^{12}$ nitidamente amparada na tipologia elaborada por Políbio. ${ }^{13}$

Cipião afirma que cada uma das formas simples, desde que mantendo "[...] aqueles vínculos que primeiro ligou os homens entre si [...] podem ser toleradas [...]. E “[...] quer um rei equitativo e sábio, quer alguns escolhidos entre os cidadãos de primeira, quer o próprio povo, embora isso seja menos recomendável, desde que não sobrevenham iniquidades ou paixões, parecem poder manter-se numa situação de não instabilidade" (Rep, I.42). O grande problema é a degeneração deste tipos toleráveis, já que todos os três possuem uma "[...] passagem perigosa e escorregadia para um tipo mau e muito próximo" (Rep, I.44). O resultado do raciocínio de Cipião é

II Itálicos no original. Salvo quando indicado, as citações são de Cicero, 2008.

12 Seria desnecessário e cansativo recuperar as diversas tipologias de formas de governo que precedem a formulada por Polibio e aqui endossada por Cícero. Basta mencionar que, convencionalmente, são isolados três tipos básicos de governo/constituição (monarquia, aristocracia, democracia) e suas respectivas degenerações (tirania, oligarquia, oclocracia). A terminologia que aqui serve de exemplo é de Polibio, apesar de Cicero beber em outras fontes do mediterrâneo antigo que possuiam como principal anseio o estabelecimento de um governo temperado caracterizado pela harmonia e concórdia. Sobre essas tipologias e suas misturas, ver: Araújo, 2013.

13 Notar que Cipião teve Políbio como seu preceptor e esta é uma das razões pelas quais Lélio pede que ele disserte sobre a República, "[...] por ser justo que falasse acerca da República o mais proeminente cidadão de primeira do Estado, mas também por me lembrar de que, com muita frequência, tu costumavas debater com Panécio, na presença de Polibio, talvez os dois Gregos mais conhecedores de questões políticas, e aduzir muitos argumentos para mostrar que, de longe, a melhor forma de constituição era aquela que os nossos antepassados nos tinha legado" (Rep, 1.34). 
sua recomendação de “[...] um quarto tipo de constituição, que seja uma moderada mistura dos três tipos [...]” indicados antes (Rep, I.45).

O ceticismo de Cipião em relação ao papel do povo no esquema menos recomendável que os demais - é indicativo de um receio em regra, entre as tipologias de formas de governo gestadas no mediterrâneo antigo, aos humores da multidão. Mas trechos abaixo Cipião mistura o povo com a própria existência da liberdade, uma vez que "[...] em nenhuma outra cidade a liberdade tem domicílio a náo ser naquela em que o poder supremo pertence ao povo" (Rep, I.47), completando que nada é mais "doce" do a liberdade e que "[...] se ela não for igual [para todos], nem sequer é liberdade!" (Rep, I.47). O povo, portanto, possui uma relação dúbia com o governo: é sua fonte de autoridade, mas é inconveniente liderando. Esta dubiedade ainda aparece quando em seguida Cipiáo aquiesce que uma constituição popular não degenerada pode garantir um bom governo (Rep, I.48-49), desde que regido por leis e ambientado na concórdia (Rep, I.48-49).

Esta dubiedade em relação ao povo é estendida aos demais tipos constitucionais. Um povo sem liberdade possui um tirano, e não um rei; e uma elite degenerada, arvorados em optimates sem o consentimento popular, é insuportável (Rep, I.50). Cipião encerra o comentário sobre a oligarquia notando que nenhuma constituição é mais disforme do que aquela que se consideram os mais ricos os melhores (Rep, I.51). Mesmo que para adiante completar, no entanto, que é entre os optimates que se encontra a moderação necessária para bem governar e que uma cidade por eles administrada "necessariamente" trará felicidade ao povo (Rep, I.52).

Cada um dos tipos constitucionais, estando todos igualmente comprometidos por vícios que lhes são inerentes (Rep, I.55), precisa de contenção. Apenas uma engenharia de governo específica, que mantivesse um perfeito equilíbrio entre os tipos constitucionais simples, pode impedir a degeneração do governo e a ruína da república. $\mathrm{O}$ papel do povo no tratado ciceroniano somente pode ser compreendido se devidamente enquadrado neste suposto equilíbrio. Daí a dubiedade sobre os termos da participação popular no governo expressa por Cipião. Entendo não se tratar de uma prevenção específica contra o elemento popular, mas uma ressalva 
em relação ao domínio de qualquer um dos três tipos constitucionais. Esta reserva, note-se, é táo comum entre os escritores do mediterrâneo antigo que Cícero parafraseia longos trechos de Platão sobre a inconveniência do comportamento da turba (Rep. I.65-68).

Cícero e Lívio podem ser contrastados com Salústio, comumente associado a uma raiz popular do republicanismo. Apesar de ser um escritor com pretensas simpatias populares ${ }^{14}$, suas consideraçóes sobre o papel do povo na dinâmica de uma comunidade política também devem ser compreendidas nos quadros de um equilíbrio perfeito entre os tipos constitucionais simples. Isso fica evidente nas consideraçôes de Salústio sobre abundância e corrupção concorrendo para minar um equilíbrio que mantinha a cidade poderosa.

Um ponto a ser sublinhado é o fato de Salústio aceitar que a virtude pode estar presente tanto entre o povo quanto entre a elite, uma vez que o autor opera com uma noçáo larga de aristocracia que abarcava tanto membros de famílias antigas quanto homens novos que ocuparam postos relevantes no governo da cidade. Ainda assim, Salústio estabelece uma clara distinção entre povo e elite (EARL, 1961, p. 18). Poderia a virtude ser cultivada pelos diferentes membros da comunidade, portanto. Mas em uma cidade corrompida, e Salústio acompanha Cícero e Lívio neste particular, são os vícios que emergem. Ao escrever sua Conjuração de Catilina (Cat), Salústio descreve isso com vivas cores.

A corrupção de Roma, em seu escrito, é resultado do avanço do luxo e do conforto. Uma situação claramente diferente do passado da cidade, quando havia entre os romanos "[...] a maior emulação pela glória: cada um se apressava a ferir um inimigo, a escalar um muro, a ser visto praticando tais façanhas; estas eram as riquezas que consideravam, esta a boa fama, esta a grande nobreza" (Cat, 7). Os "bons costumes" eram cultivados tanto na paz quanto na guerra e a concórdia alcançou seu ponto máximo: "Rixas, discórdias e rivalidades, eles [os romanos] as tinham com os inimigos, mas cidadãos com cidadão só da virtude disputavam" (Cat. 9). O conflito do passado se dava entre homens virtuosos e o resultado era o engrandecimento

14 Se esta simpatia era Cesarista é uma discussão que não cabe no momento e não compromete meu argumento. 
da comunidade. O conflito na Roma de Salústio se dava pautado pela avareza. O próprio conspirador, Catilina, é descrito com um criminoso que encontra em uma cidade corrompida um ambiente favorável ao seu desenvolvimento de seu caráter (Cat, 14). O retrato final do conspirador, na reprodução de um discurso seu aos soldados que iriam para uma batalha perdida, indica a mesma coisa: o ambiente corrupto de Roma compromete o comportamento dos cidadãos (Cat, 60).

O papel da elite neste processo de corrupção é mais realçado que o do povo. As tratativas de Jugurta com o Senado romano, descritas em Guerra de Jugurta (Jug) são esclarecedoras. Jugurta era filho ilegítimo do rei de uma comunidade que possuía antigos laços diplomáticos com Roma e aspirava ao trono. Resistindo ao seu avanço estavam os herdeiros legítimos do trono. A narrativa de Salústio inicia justamente com o envio de legados de Jugurta ao Senado romano buscando, via suborno, apoio para sua aspiração ao trono (Jug, 13). O suborno funciona (Jug, 16), mas como Jugurta não cumpre os termos do acordo comprado. Um novo debate tem lugar no Senado, e novamente Jugurta é atendido em seus pleitos, fazendo Salústio lamentar que: "Assim foi o bem público, conforme costuma suceder na maior parte dos casos, vencido pelo interesse particular" (Jug, 25).

Se a elite dava claros sinais de corrupção, o retrato do general Mário é um elogio às virtudes do homem comum. Um dos possíveis encarregados de lidar com as ofensivas militares de Jugurta, Mário faz um longo discurso perante a assembleia popular. Segundo Salústio, mantendo o hábito de vituperar contra a nobreza (Jug, 84). Através das palavras de Mário, Salústio louva as qualidades dos homens comuns. Apesar do papel relevante que possui na dinâmica política de Roma, Mário orgulha-se de sua origem humilde. Solicitando autorização popular para sua campanha militar, o general admite não poder "[...] ostentar os retratos ou os triunfos ou os consulados de meus maiores [...]"; mas se necessário for, pode ostentar "recompensas militares" e "[...] as cicatrizes de luta frente a frente". Um homem, portanto, que não possui origem nobre; mas que, por meio de seu engenho, alcança a nobreza "[...] não deixada por herança, como a deles a eles [elite romana], mas por mim adquirida com meus muitos trabalhos e perigos" (Jug, 25). 
Ao longo de Jugurta e Catilina, é possível identificar outros exemplos de uma visão circunstanciada sobre o caráter do povo e da elite romana. Ilustrativo é o argumento montado por Salústio para descrever o declínio de Roma, onde povo e elite são igualmente responsáveis pela corrupção. $\mathrm{E}$ as circunstâncias têm um papel relevante no processo.

Salústio inicia pelo suposto de que facçóes se apoderaram da Roma de seu tempo, num processo recente que remonta à destruição de Cartago, quando a paz e abundância "[...] daquelas coisas que os mortais consideram mais importante". Antes disso, Senado e povo "[...] tratavam em conjunto da república calma e pacificamente e não havia entre os cidadáos lutas pela glória e pelo poder: o medo do inimigo mantinha a cidade nos bons costumes". O resultado é que a nobreza começa a "transformar em capricho a autoridade" e a plebe, por sua vez, faz o mesmo com a liberdade e "[...] cada um tratava de si e para si roubava e saqueava". A república, neste conflito degenerado, resta "despedaçada" (Jug, 41). A ruína de Roma é resultado de um desarranjo num sistema que prezava pelo equilíbrio que, dessa forma, conseguia conter os vícios inerentes a cada forma simples de constituição e, por analogia, as tendências ao mau comportamento intrínsecas a plebeus e patrícios.

\section{Conclusão}

Minha intenção com este paper é indicar aos interessados no republicanismo que o pensamento político romano pode ser uma fonte interessante de consulta para elaboração de modelos e análises políticas. Além de uma vigorosa contribuição para o debate sobre o conceito de liberdade, Roma pode ser capaz de alimentar outras frentes de estudo. A relação entre povo e elite recentemente emergiu nos debates entre republicanos e seus críticos. Ao mesmo tempo, a realidade de Roma passa a ser lida de forma inovadora, com uma lente fortemente informada pelas demandas da teoria política contemporânea. Porém, para que esta consulta seja eficiente acredito ser necessária uma leitura e/ou consulta que será manuseável de forma precária. Consultar as respostas que escritores romanos elaboraram para suas angústias particulares pode, de alguma maneira, alargar o ferramental intelectual disponível para a compreensão sobre nossos próprios dilemas. Um dilema caro aos romanos, que pretendi apresentar, é como equalizar 
povo e elite na dinâmica de uma comunidade política, em geral, e na dinâmica romana em especial.

Uma sugestão de como enfrentar o dilema é compartilhada pelos três escritores romanos aqui mencionados: manter um equilíbrio entre povo e elite, em um arranjo formado pelas três formas simples de governo. Tendo esta constituição mista como quadro significante de suas assertivas, pode ser um equívoco a insistência da crítica moderna em debater se é no povo ou na elite que, entre os escritores romanos, estava a virtude necessária para o bom governo. Em suas análises, povo e elite possuem a mesma quantidade de vícios e virtudes - embora em cada um dos autores mobilizados possa ser identificada alguma particularidade em avançar o argumento. Isso implica que também pode estar equivocada a busca, entre autores romanos, de uma justificativa para a procura de um único ente responsável pelo governo.

Eu apresentei algumas sequências de textos importantes de cada um dos romanos discutidos. Elas não devem ser tomadas como as únicas em que a dualidade que apontei, e suas implicaçóes para teoria política, emerge em seus escritos. Nestes trechos, é verdade, esta dualidade aparece de forma saliente. Dada a articulaçáo do significado destes trechos com outras dimensóes de seus escritos, entendo ser justo tomar como uma regra a recusa dos escritores romanos aqui considerados em endossar um regime político em que plebe ou elite tenham proeminência no governo.

Ao se perceberem em um mundo político em ruínas, estes escritores revelam em seus escritos muito mais suas angústias e recomendaçóes do que a realidade em que estavam imersos. $\mathrm{O}$ elogio a um equilíbrio que teria se perdido se manifesta na história de Lívio, no tratado de Cícero e nas histórias de Salústio. A crítica moderna poderá se nutrir de seus escritos se os ler menos como uma análise do que Roma talvez tenha sido e mais como aquilo que desejavam ser. Além disso, parece necessário distinguir o pensamento político de romano do republicanismo. Pettit, ao advogar a raiz romana do ramo do republicanismo que cultiva, pode estar abrindo um flanco para um justo ceticismo sobre o compromisso democrático do republicanismo - como aquele expresso por Urbinati (2011). Como uma tradição histórica, o republicanismo é ativado em contextos distintos. 
Mantêm temas, abandona outros, inova. O republicanismo do século XXI tem o seu próprio contexto e suas angústias, onde a democracia é um valor universal. Talvez por terem falado sobre democracia com menos reverência que nós, os romanos nos indiquem coisas que náo vemos por estarmos enfeitiçados por nossa própria época.

\section{Referências}

ARAÚJO, C. R. R. de. A forma da República: da constituiçấo mista ao Estado. São Paulo: Editora WMF Martins Fontes, 2013.

CÍCERO. The Republic; The Laws. Tradução de Clinton W. Keyes. Cambridge; London: Harvard University Press, 1928.

CÍCERO. Tratado da República [De Re Publica]. Tradução, introdução e notas de Francisco de Oliveira. Portugal: Círculo de Leitores; Tema e Debates, 2008.

EARL, D. C. The Political Thought of Sallust. Cambridge: Cambridge University Press, 1961.

HAMMER, D. Roman Political Thought and the Modern Theoretical Imagination. Norman: University of Oklahoma Press, 2008.

HAMMER, D. Roman Political Thought: from Cicero to Augustine. Cambridge: Cambridge University Press, 2014.

KAPUST, D. Skinner, Pettit e Livy: the conflict of the orders and the ambiguity of republican liberty. History of Political Thought, 25, n. 3, p. 378-401, 2004.

KAPUST, D. Republicanism, Rhetoric and Roman Political Thought: Sallust, Livy, and Tacitus. New York: Cambridge University Press, 2011.

KAPUST, D. J.; TURNER, B. P. Democratical Gentlemen and the Lust for Mastery: Status, Ambition, and the Language of Liberty in Hobbes's Political Thought. Political Theory, v. 41, p. 648-675, 2013.

LINTOT, A. The Constitution of the Roman Republic. Oxford: Oxford University Press, 1999.

MCCORMICK, J. Machiavellian Democracy: Controling Elites with Ferocious Populism. American Political Science Review, v. 95, n. 2. p. 297-313, 2001.

MCCORMICK, J. Machiavelli against Republicanism: on the Cambridge School's 'Guicciardini' Moments. Political Theory, v. 31, n. 5, p. 615-643, 2003.

MCCORMICK, J. Machiavellian Democracy. New York: Cambridge University Press, 2011.

MCCORMICK, J. Machiavellian Democracy in the Good Society. The Good Society, v. 21, n. 1, p. 90-117, 2012. 
LÍVIO. História de Roma. Tradução de Paulo Matos Peixoto. São Paulo: Paumape, 1989.

LIVY. History of Rome - Books I-II. Translated by B. O. Foster. Cambridge: Harvard University Press, 1919.

PETTIT, E. Tratado Elementar de Direito Romano. Tradução de Jorge Luís Custódio Porto. Campinas: Russel Editores, 2003.

PETTIT, P. Republicanism: A Theory of Freedom and Government. Oxford: Oxford University Press, 1997.

PETTIT, P. On the people's terms: a republican theory and model of democracy. New York: Cambridge University Press, 2012.

PETTIT, P. Two Republican Traditions. In: NIEDERBERGER, A.; SCHINK, P. (Ed.). Republican Democracy: liberty, law and politics. Edinburgh: Edinburgh University Press, 2013. p. 169-204.

POLIBIOS. História. Tradução de Mário da Gama Kury. Brasília: UNB, 1985.

SALÚSTIO. Obra Completa. Tradução e introdução de Agostinho da Silva. Lisboa: Livros Horizonte, 1974.

SILVA, R. Liberdade e lei no neo-republicanismo de Skinner e Pettit. Lua Nova, v. 74, p. 151-194, 2008 .

SILVA, R. Maquiavel e o conceito de liberdade em três vertentes do novo republicanismo. Revista Brasileira de Ciências Sociais, v. 25, p. 37-58, 2010.

SILVA, R. Republicanismo neo-romano e democracia contestatória. Revista de Sociologia Política, v. 19, n. 39, p. 35-51, 2011.

SKINNER, Q. As fundaçóes do pensamento político moderno. São Paulo: Cia das Letras, 1996.

SKINNER, Q. Liberdade antes do Liberalismo. Tradução de Raul Fiker. São Paulo: Unesp, 1999.

URBINATI, N. Republicanism: democratic or popular?. The Good Society, v. 20, n. 2, p. 157169, 2011.

URBINATI, N. Competing for Liberty: the republican critique of democracy. American Political Science Review, v. 106, n. 3, p. 607-621, 2012.

URBINATI, N. Democracy Disfigured - opinion, truth, and the people. Cambridge; Massachutes; London: Harvard University Press, 2014.

WALKER, W. Sallust and Skinner on Civil Liberty. European Journal of Political Theory, v. 5, n. 3, p. 237-259, 2006. 


\section{People and elite in classical republicanism}

\section{Abstract}

Within the scope of the Republican Revival, there is a renewed interest in Roman political thought. Formulations based on the republican tradition of political thought have entered the field of Political Theory since the neo-Roman argument was included in the debate on the concept of freedom. Correlated to this initial movement, republicanism is being employed to tackle an increasing of theoretical dilemmas. One currently debated topic is the role republicanism assigns to the democratic element in its political models. The aim of this paper is to analyze three key authors of Roman political thought - Cicero, Sallust and Lyvi - and their respective understandings of the role of the people and the democratic element in the political dynamics of Rome. I intend to convince the reader that modern interpretations may be making a mistake by seeking among these authors a clear justification for establishing the people as the protagonists of the political process.

Keywords: Rome, Repubicanism, People, Elite

Recebido em 03/10/2017

Aprovado em 04/10/2018 